\title{
Hybrid Dielectric Resonator Antenna Composed of High-Permittivity Dielectric Resonator for Wireless Communications in WLAN and WiMAX
}

\author{
Yih-Chien Chen \\ Department of Electrical Engineering, Lunghwa University of Science and Technology, Shiang, Taoyuan County, \\ 33306 Gueishan, Taiwan \\ Correspondence should be addressed to Yih-Chien Chen, ycchenncku@yahoo.com.tw
}

Received 26 January 2012; Accepted 22 May 2012

Academic Editor: Dalia N. Elshiekh

Copyright () 2012 Yih-Chien Chen. This is an open access article distributed under the Creative Commons Attribution License, which permits unrestricted use, distribution, and reproduction in any medium, provided the original work is properly cited.

The-hybrid dielectric resonator antenna consisted of a cylindrical high-permittivity dielectric resonator, a rectangular slot, and two-rectangular patches were implemented. The hybrid dielectric resonator antenna had three resonant frequencies. The lower, middle, and higher resonant frequencies were associated with the rectangular slot, rectangular patches, and dielectric resonator, respectively. Parametric investigation was carried out using simulation software. The proposed hybrid dielectric resonator antenna had good agreement between the simulation results and the measurement results. The hybrid dielectric resonator antenna was implemented successfully for application in 2.4/5.2/5.8 GHz of WLAN and 2.5/3.5/5.5 GHz of WiMAX simultaneously.

\section{Introduction}

Many commercial applications, including mobile radio and wireless communications, use microstrip antennas. However, these microstrip antennas have a limited range of sizes, bandwidth, and efficiency. On the other hand, dielectric resonator (DR) antenna is attractive due to its small-size, high-radiation efficient, and ease of excitation $[1,2]$. Many investigations of DR antenna composed of DR with relatively small permittivity around 10 have examined to enhance radiation capability [3-5]. Many works have focused on using DR with high-permittivity to promote device miniaturization when DR antenna operated at low frequency. However, these antennas composed of high-permittivity DR had a small bandwidth [6].

The use of dual band antennas in WLAN (wireless local area network) has been increasing rapidly in the last decade. Dual band antennas applied in ISM (Industrial, Scientific, Medical, 2.4-2.484 GHz) in low band of WLAN. At the same time, dual band antennas also applied in high band of WLAN, including HIPERLAN (high-performance radio local area network, $5.15-5.35 \mathrm{GHz}$ ), and UNII (unlicensed national information infrastructure, 5.725$5.825 \mathrm{GHz})$. Dual band DR antennas were implemented by placing a parasitic element near the radiation part [7], or stacking many DR [8]. On the other hand, associating with the rapid development of WiMAX (worldwide interoperability for microwave access, $2.5-2.69,3.3-3.8$, and $5.25-5.85 \mathrm{GHz}$ ), there is an increasing demand for antennas suitable for WLAN/WiMAX simultaneously. In this paper, the hybrid DR antenna, consisting of a cylindrical highpermittivity dielectric resonator, a rectangular slot, and tworectangular patches, operated in the ISM, HIPERLAN, UNII, and WiMAX bands simultaneously. Multiband hybrid DR antenna was implemented. However, the volume of hybrid DR antenna did not increase. The radiating resonators in the hybrid DR antenna were assembled tightly and resonated at three frequencies. The characteristics of hybrid DR antenna, such as return loss, radiation pattern, and gain were measured and discussed. 

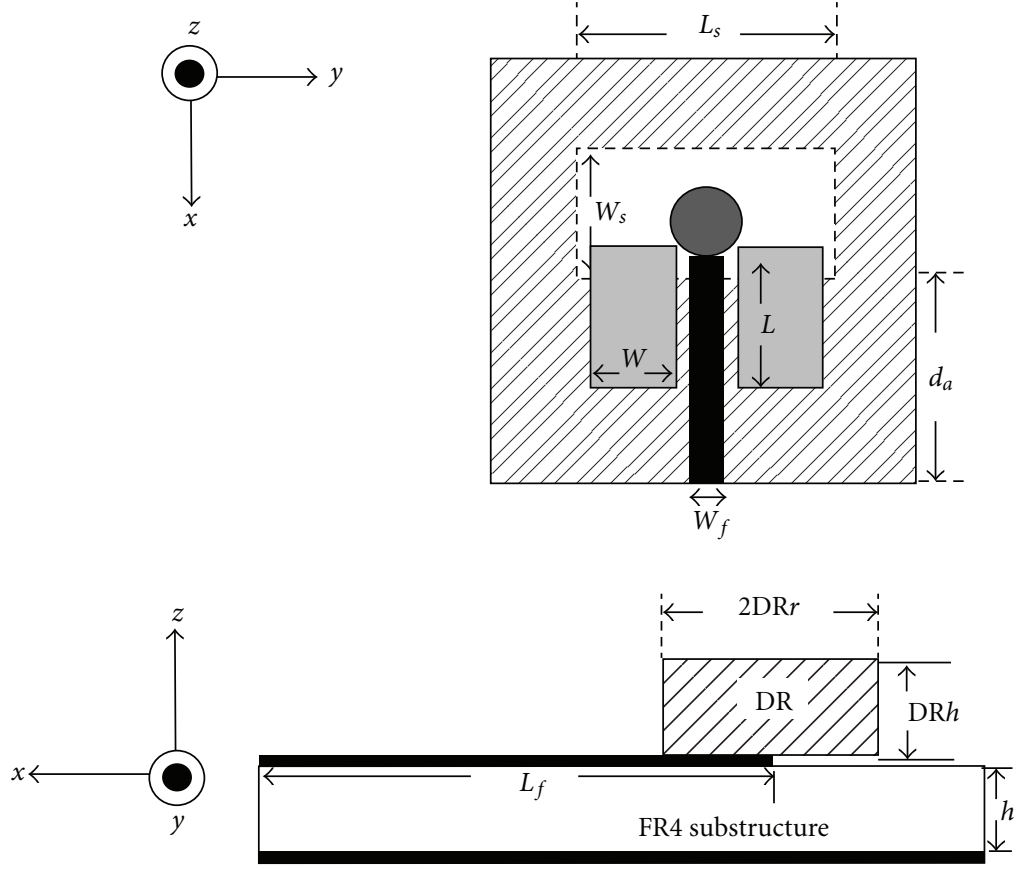

FIGURE 1: Configuration of hybrid DR antenna consisted of a rectangular slot, a cylindrical high-permittivity DR, and two-rectangular parasitic patches.

\section{Design and Measurement}

The resonant frequency of the cylindrical DR antenna excited at the dominant $\mathrm{TM}_{110}$ mode is [1]

$$
f_{110}^{\mathrm{TM}}=\frac{c}{2 \pi r \sqrt{\varepsilon_{\mathrm{ra}}}} \sqrt{X_{11}^{\prime 2}+\left(\frac{\pi r}{2 h}\right)^{2}},
$$

where $X_{11}^{\prime}=1.841$ is the first zero of the equation $J_{1}^{\prime}(x)=0$, and $c$ is the speed of light in a vacuum. The parameters of $r, h$, and $\varepsilon_{\mathrm{ra}}$ is the radius, height, and permittivity of the DR, respectively. Figure 1 shows the configuration of the proposed hybrid DR antenna, consisting of a rectangular slot, a cylindrical high-permittivity DR, and two-rectangular patches. The rectangular RF4 substrate had dimensions of $50.0 \times 50.0 \mathrm{~mm}^{2}$ and thickness of $1.6 \mathrm{~mm}$. The cylindrical DR was fed with microstrip line. The microstrip feed line was placed below the centerline ( $x$-axis in the figure) of the DR. Dimensions of the microstrip feed line on FR4 substrate was calculated by close-form formulas given in [9], assuming infinite ground plane and finite dielectric thickness. The microstrip feeding line had length $L_{f}$ of $28.0 \mathrm{~mm}$ and width of $W_{f}$ of $3.0 \mathrm{~mm}$. The DR had a highpermittivity $\varepsilon_{\mathrm{ra}}=25$, radius $r=4.0 \mathrm{~mm}$, and height $h=$ $3.0 \mathrm{~mm}$. The DR was a low-loss ceramic system composed of $\mathrm{La}(\mathrm{MgSn})_{0.5} \mathrm{O}_{3}$ and $\mathrm{CaTiO}_{3}$. The rectangular slot on the back side of the FR4 substrate fed with microstrip line, resonated at approximately half-guided wavelength, $\lambda_{\mathrm{gs}}$, where $\lambda_{\mathrm{gs}}$ was the guided wavelength of the slot. The length of rectangular slot was $31 \mathrm{~mm}$. Adjusted the length of the rectangular slot adjusted the lower resonance frequency. Adjusting the width of the rectangular slot enabled impedance matching. The bandwidth at lower resonant frequency could be adjusted by adjusting the width of the rectangular slot. The rectangular patches were placed at the two sides of microstrip feed line. The electric field distributions along the top and bottom edges of the rectangular patches were in-phase, and hence these edges were referred to as radiating edges. The electric field distributions in the right and left edges of the rectangular patches were out of phase, and hence these edges were referred to as nonradiating edges (NREs) [10]. The rectangular patches were designed at a resonant frequency of $3.5 \mathrm{GHz}$. The lengths of the rectangular patches were designed to be $\lambda_{\mathrm{gp}} / 2$, where $\lambda_{\mathrm{gp}}$ was the guided wavelength of the rectangular patch [11]. The middle resonance frequency could be adjusted by adjusting the length of the rectangular patches. Impedance matching could be realized by adjusting the width of the rectangular patch. Therefore, the bandwidth at middle frequency could be adjusted by adjusting the width of the rectangular patch. In simulation, the conducting grounds and the substrates were assumed to be finite in transverse plane. Reflection coefficient was measured on a PNA-L network analyzer (N5230A). Radiation patterns were measured in a chamber. A standard-double-ridged horn antenna was used as a transmitting antenna. The hybrid DR antenna was mounted on a position which was controlled by a computer.

\section{Parametric Study}

Figures 2 and 3 show the simulation return loss of the hybrid DR antenna with different DR height and DR permittivity, respectively. From the results, the upper resonant frequency decreased from 5.70 to $5.55 \mathrm{GHz}$ as DR height increased from 2 to $4 \mathrm{~mm}$. This phenomenon can be explained by 


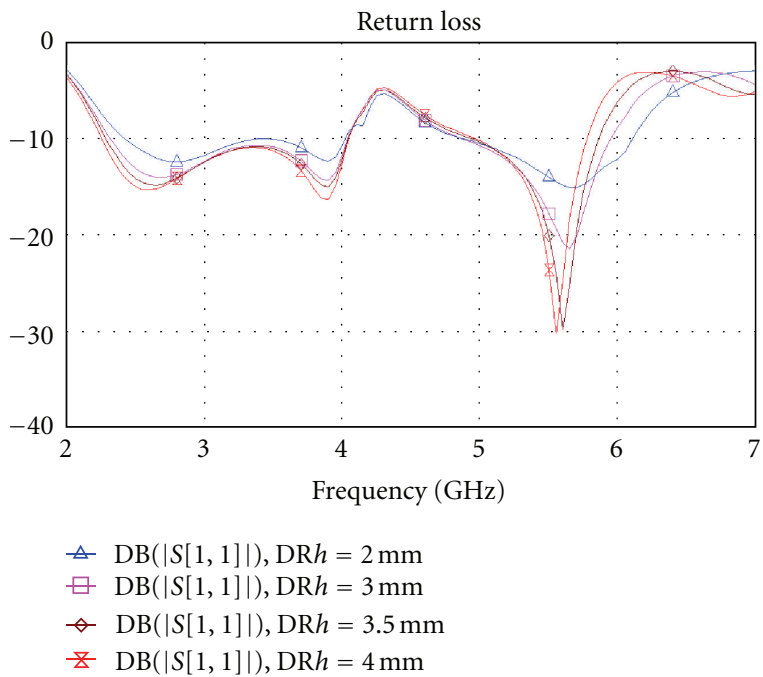

Figure 2: Simulation return loss of hybrid DR antenna with different DR height.

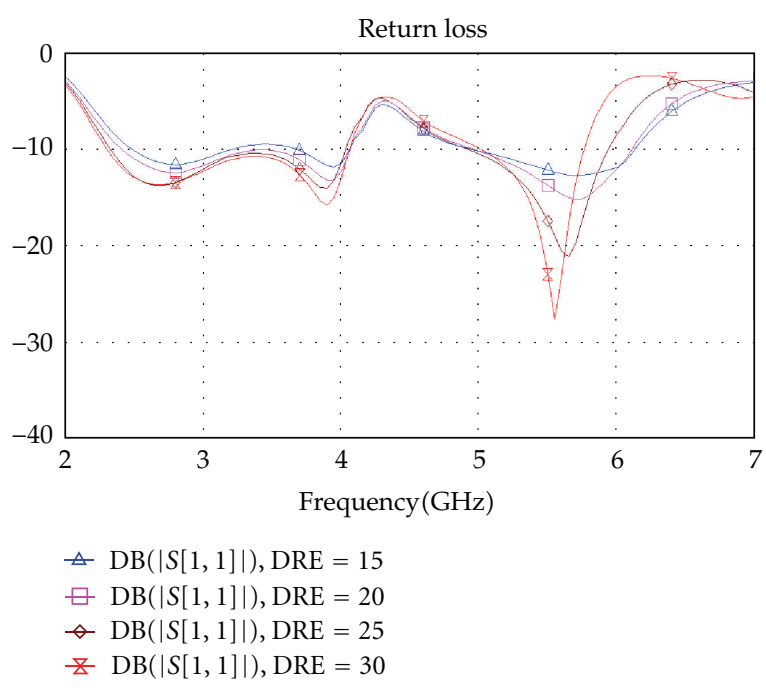

FIGURE 3: Simulation return loss of hybrid DR antenna with different DR permittivity.

using (1). The larger the DR height enabled the lower the resonant frequency of DR antenna. The upper resonant frequency decreased from 5.74 to $5.55 \mathrm{GHz}$ as DR permittivity increased from 15 to 30 . As shown in (1), the larger the DR permittivity enabled the lower the resonant frequency of DR antenna. The upper resonant frequency of hybrid DR antenna was demonstrated to be dominated by the DR parameters. The middle resonant frequency nearly unchanged as DR parameters varied. Additionally, the lower resonant frequency was slightly affected by the DR parameters. The variation in low resonant frequency may have been caused by the resonant length of rectangular slot was approximately half-guided wavelength. A higher the DR height and a larger the DR permittivity, is associated with a

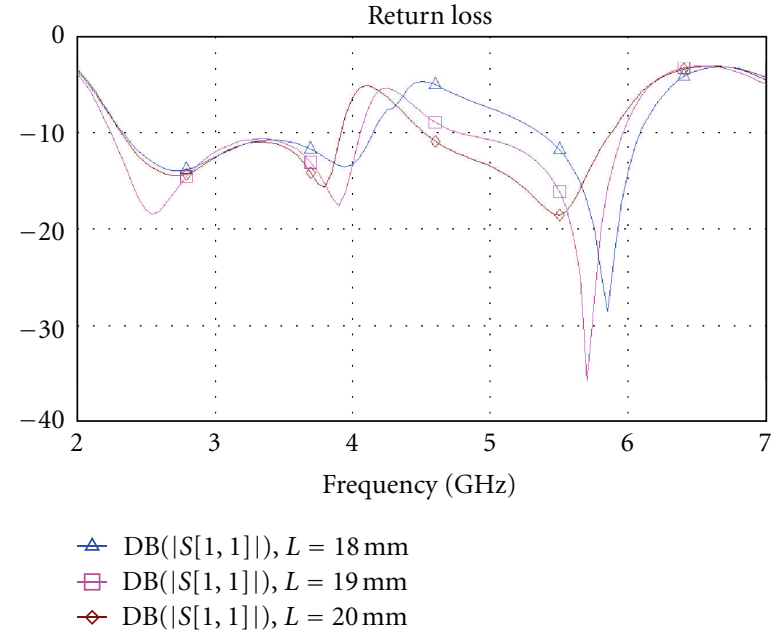

FIGURE 4: Simulation return loss of hybrid antenna with different rectangular patch length.

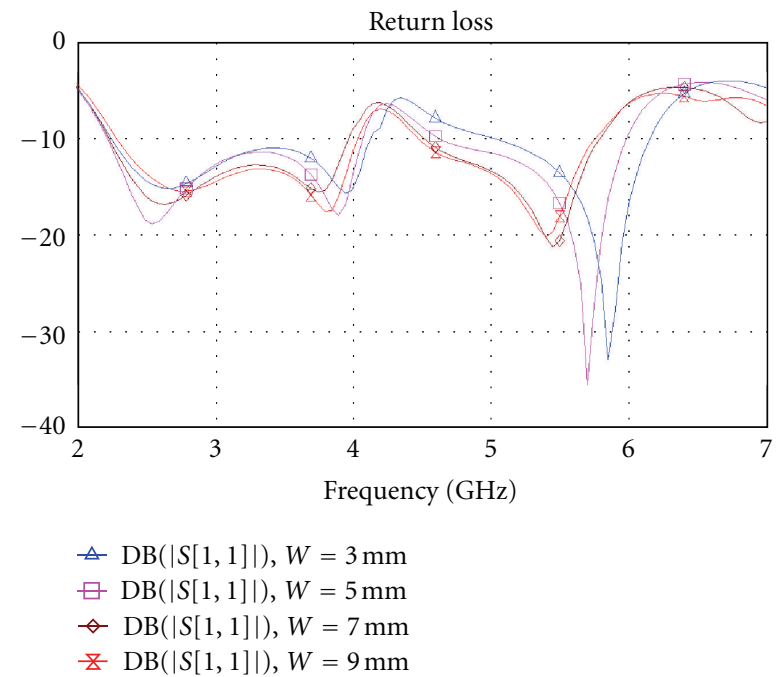

Figure 5: Simulation return loss of hybrid DR antenna with different rectangular patch width.

larger effective permittivity and, therefore, a lower resonant frequency.

Figures 4 and 5 show the simulation return loss of the hybrid antenna with different length and width of rectangular patch, respectively. The middle resonant frequency decreased from 3.95 to $3.80 \mathrm{GHz}$ as the length of rectangular patch increased from 18 to $20 \mathrm{~mm}$. Since the resonant length of rectangular patch was half-guided wavelength, the longer the length of rectangular patch enabled the lower the resonant frequency. The influence of the width of rectangular patch on the middle resonant frequency was not evident compared with that of the influence of the length of rectangular patch. The higher resonant frequency decreased as the rectangular patch length and width increased. By increasing the rectangular patch length and width, the effective permittivity of the hybrid DR antenna increased. 


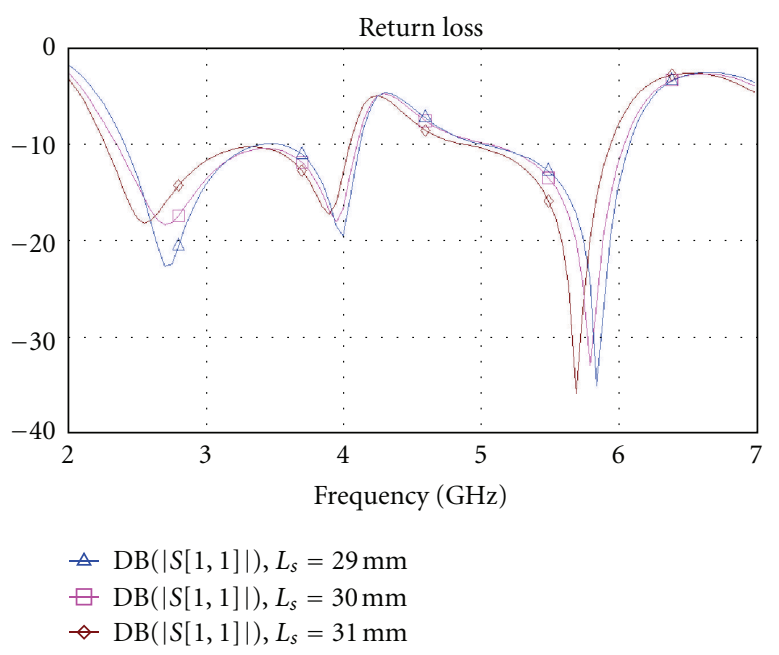

FIGURE 6: Simulation return loss of hybrid DR antenna with different rectangular slot length.

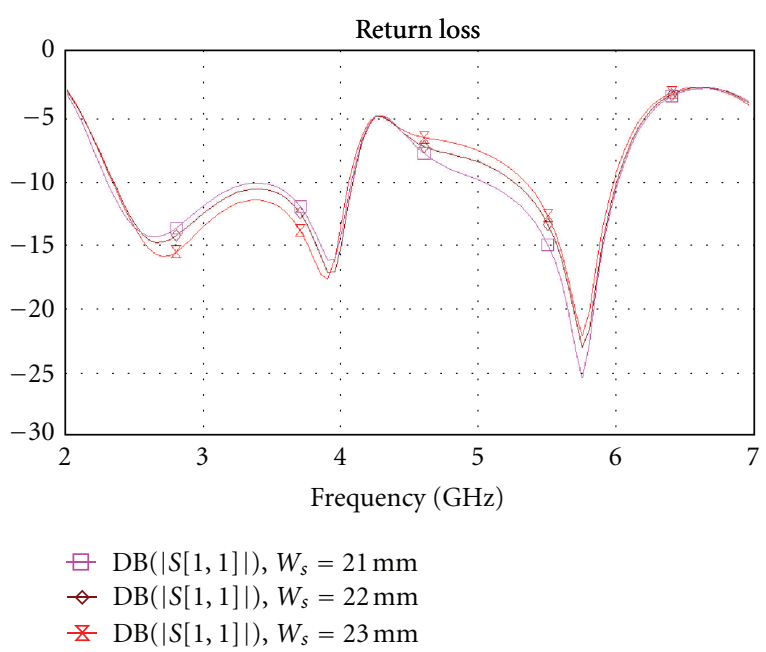

FIgURE 7: Simulation return loss of hybrid DR antenna with different rectangular slot width.

This leaded to reduce the resonant frequency of the DR antenna.

Figures 6 and 7 present the simulation return loss of the hybrid DR antenna with different length and width of rectangular slot, respectively. The lower resonant frequency decreased from 2.70 to $2.55 \mathrm{GHz}$ as the length of rectangular slot increased from 29 to $31 \mathrm{~mm}$. This was because of the resonant length of rectangular slot was half-guided wavelength. The longer the length of rectangular slot enabled the lower the resonant frequency. The higher resonant frequency of the hybrid DR antenna decreased slightly as the length of rectangular slot increased. This was associated with the effective height of DR increased as the length of rectangular slot increased. The influence of the width of rectangular slot on the resonant frequency was slight. The return loss reduced in the lower and middle resonant

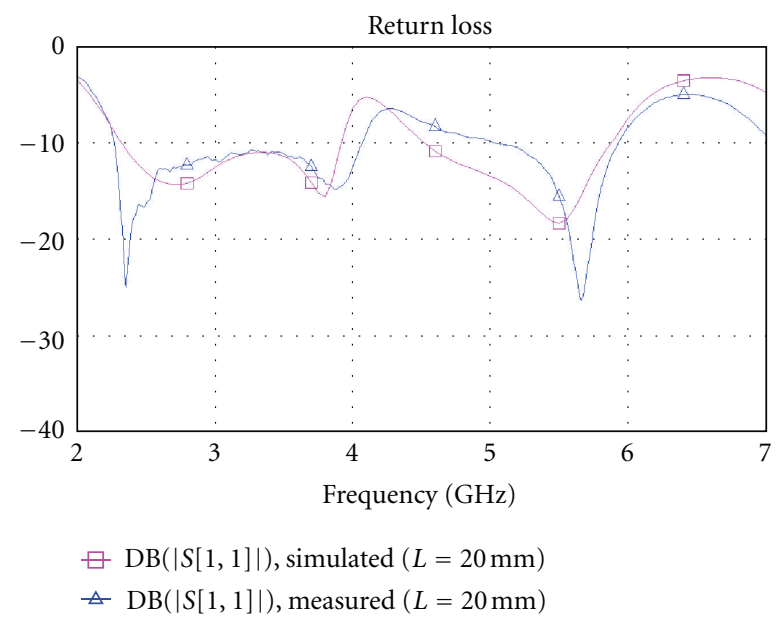

FIGURE 8: Measurement and simulation return loss of hybrid DR antenna.

frequencies as the width of rectangular slot increased. On the contrary, the return loss increased in the higher band as the width of rectangular slot increased.

\section{Results and Discussion}

Figure 8 shows the measurement and simulation return loss of the hybrid DR antenna. The measurement resonant frequency was close to the simulation resonant frequency. The lower, middle, and higher resonant frequencies were associated with the rectangular slot, the rectangular patches, and $\mathrm{DR}$, respectively. The return losses were $-25,-15$, and $-27 \mathrm{~dB}$ at $2.36,3.88$, and $5.66 \mathrm{GHz}$, respectively. There was a $10 \mathrm{~dB}$ return loss bandwidth of $1789 \mathrm{MHz}$ (2273$4062 \mathrm{MHz})$ and $791 \mathrm{MHz}(5127-5918 \mathrm{MHz})$. Alternatively, the antenna had a $10 \mathrm{~dB} S_{11}$ bandwidth of $56 \%$ and $14 \%$, which covered the required bandwidth $2400-2484 \mathrm{MHz}$, $2500-2690 \mathrm{MHz}, 3300-3800 \mathrm{MHz}, 5150-5350 \mathrm{MHz}, 5250-$ $5850 \mathrm{MHz}$, and $5725-5825 \mathrm{MHz}$, simultaneously. The bandwidth was enough for many practical applications. The bandwidth at the higher resonant frequency, associating with the cylindrical DR with high-permittivity, was larger than the typical value of $6 \sim 12 \%$ of conventional DR antenna using DR with permittivity around 10 [2-5].

Figure 9 displays the radiation patterns of the hybrid DR antenna in the $x z$-plane and $y z$-plane at resonant frequencies of $2.36 \mathrm{GHz}, 3.88 \mathrm{GHz}$, and $5.66 \mathrm{GHz}$. The radiation patterns were stable across the return loss $\leq 10 \mathrm{~dB}$ bands. The radiation patterns were almost omnidirectional in the $x z$ plane at resonant frequencies of 2.36 and $3.88 \mathrm{GHz}$. The radiation patterns in the $y z$-plane at resonant frequencies of $2.36 \mathrm{GHz}, 3.88 \mathrm{GHz}$, and $5.66 \mathrm{GHz}$ were symmetrical about the broadside direction and rolled-off as the elevation angle increased from broadside until about $90^{\circ}$. The crosspolarized patterns were about $15 \mathrm{~dB}$ less than the copolarized patterns in the broadside direction $\left(\theta=0^{\circ}\right)$ at 2.36 and $3.88 \mathrm{GHz}$. Radiation patterns at $2.36 \mathrm{GHz}$ and $3.88 \mathrm{GHz}$ were similar to conventional rectangular slot 


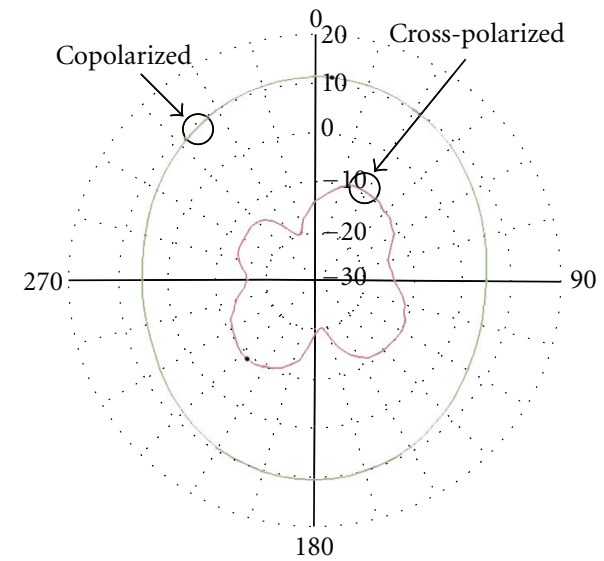

(a)

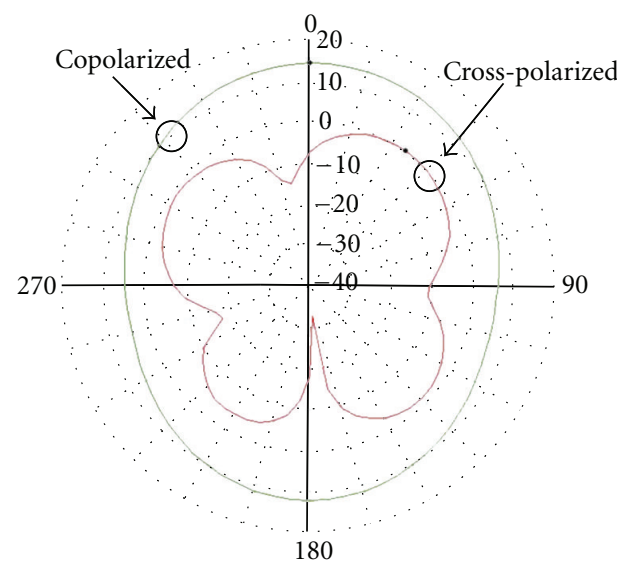

(c)

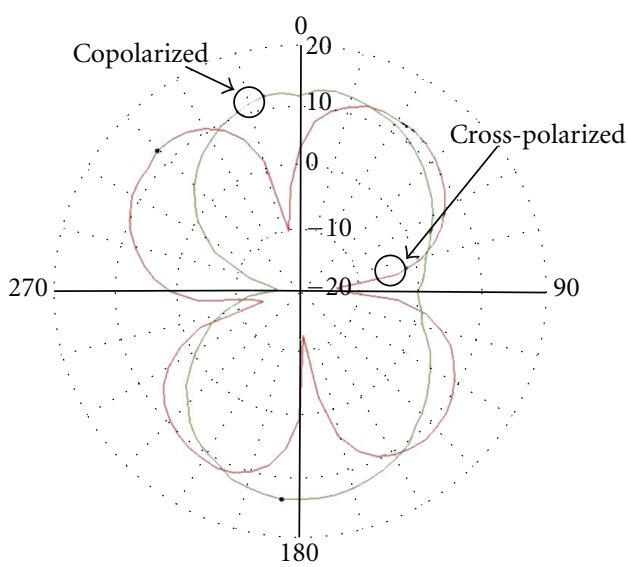

(e)

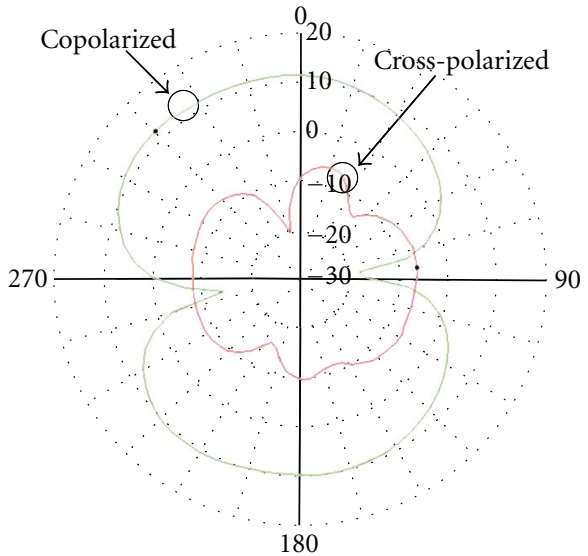

(b)

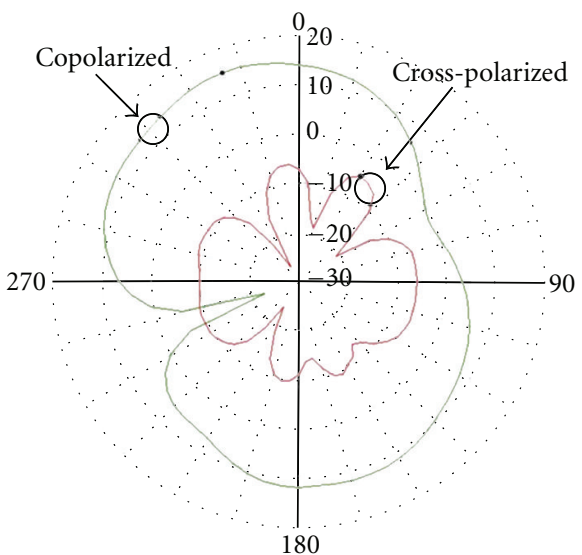

(d)

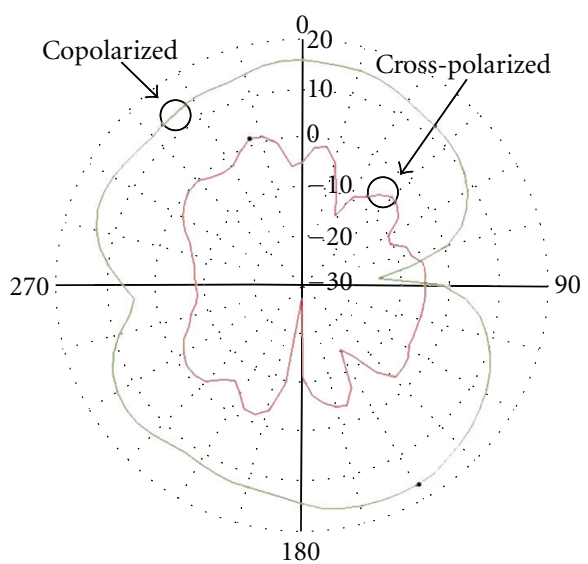

(f)

FIGURE 9: Radiation patterns of hybrid DR antenna at resonant frequency of (a) $2.36 \mathrm{GHz}$ in the $x z$-plane, (b) $2.36 \mathrm{GHz}$ in the $y z$-plane (c) $3.88 \mathrm{GHz}$ in the $x z$-plane, (d) $3.88 \mathrm{GHz}$ in the $y z$-plane, (e) $5.66 \mathrm{GHz}$ in the $x z$-plane, and (f) $5.66 \mathrm{GHz}$ in the $y z$-plane.

antenna and rectangular patch antenna, respectively. The radiation patterns at $5.66 \mathrm{GHz}$ on the DR side were similar to those of the conventional DR antenna [12, 13], and the difference on the substrate side was associated with backlobe radiation from the slot. Large cross-polarization was observed at $5.66 \mathrm{GHz}$. However, large cross-polarization became an advantage for practical applications. The wave propagated with multiple reflections between the transmitter and receiver in indoor applications.

Figures 10 and 11 display the gain of the proposed antenna for operating frequencies from 2.4 to $2.9 \mathrm{GHz}$ and from 3.3 to $5.9 \mathrm{GHz}$, respectively. The peak gains were about 


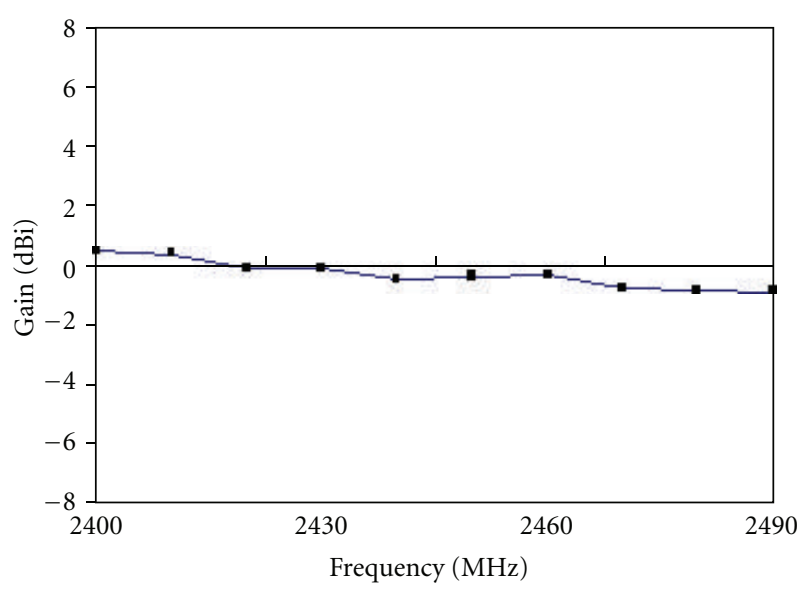

FIGURE 10: Measured gains of hybrid DR antenna for operating frequencies from 2.4 to $2.9 \mathrm{GHz}$.

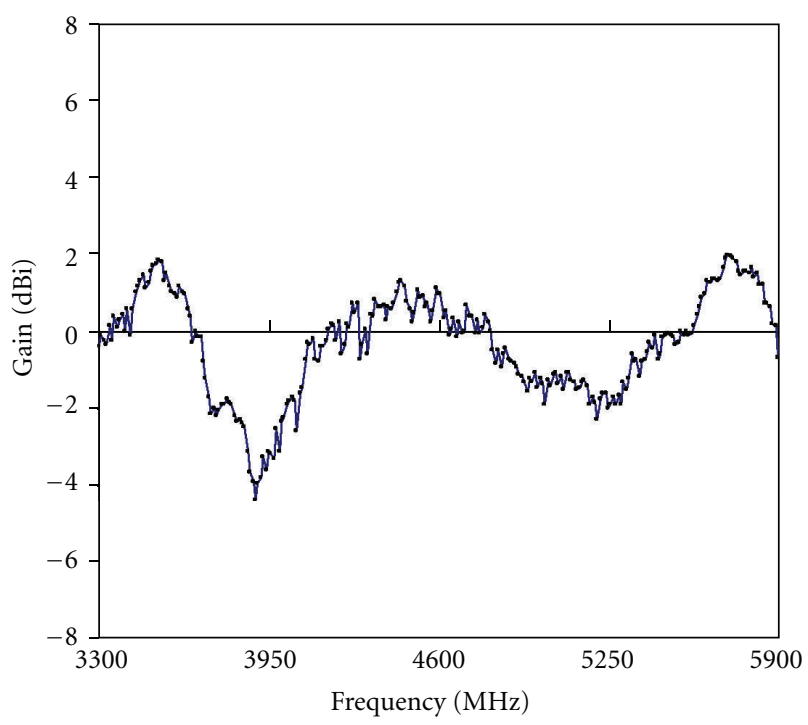

FIGURE 11: Measured gains of hybrid DR antenna gain for operating frequencies from 3.3 to $5.9 \mathrm{GHz}$.

$0.5,-0.6$, and $1.9 \mathrm{dBi}$ in the ISM, HIPERLAN, and UNII bands, respectively. The gain variations were 1.4, 1.6, and $0.4 \mathrm{dBi}$ for frequencies within the ISM, HIPERLAN, and UNII bands, respectively. The peak gains were about 1.9 and $2.0 \mathrm{dBi}$ in the 3.5 and $5.5 \mathrm{GHz}$ WiMAX bands, respectively. The gain variations were 4.0 and $3.9 \mathrm{dBi}$ for frequencies within the 3.5 and $5.5 \mathrm{GHz}$ WiMAX bands, respectively.

\section{Acknowledgment}

This work was supported by the National Science Council in Taiwan under Grant no NSC 100-2622-E-262-007-.

\section{References}

[1] S. A. Long, M. W. McAllister, and L. C. Shen, "The resonant cylindrical dielectric cavity antenna," IEEE Transactions on Antennas and Propagation, vol. 31, no. 3, pp. 406-412, 1983.

[2] R. K. Mongia, A. Ittibipoon, and M. Cuhaci, "Low profile dielectric resonator antennas using a very high permittivity material," Electronics Letters, vol. 30, no. 17, pp. 1362-1363, 1994.

[3] R. A. Kranenburg, S. A. Long, and J. T. Williams, "Coplanar waveguide excitation of dielectric resonator antennas," IEEE Transactions on Antennas and Propagation, vol. 39, no. 1, pp. 119-122, 1991.

[4] K. M. Luk, M. T. Lee, K. W. Leung, and E. K. N. Yung, "Technique for improving coupling between microstripline and dielectric resonator antenna," Electronics Letters, vol. 35, no. 5, pp. 357-358, 1999.

[5] Y. X. Guo and K. M. Luk, "On improving coupling between a coplanar waveguide feed and a dielectric resonator antenna," IEEE Transactions on Antennas and Propagation, vol. 51, no. 8, pp. 2144-2146, 2003.

[6] Y. C. Chen and K. H. Chen, "Low-profile dielectric resonator antenna with high-permittivity for application in WiMAX," Microwave and Optical Technology Letters, vol. 51, no. 7, pp. 1652-1654, 2009.

[7] Y. N. Wang, Y. C. Chen, and K. H. Chen, "Dual band hybrid dielectric resonator antenna for application in ISM and UNII band," IEICE Transactions on Communications, vol. 93, no. 10, pp. 2662-2665, 2010.

[8] L. H. Salman, D. Kajfez, and A. A. Kishk, "Dielectric resonator direction finding antenna," International Journal of Antennas and Propagation, vol. 2011, Article ID 184942, 7 pages, 2011.

[9] G. P. Junker, A. A. Kishk, and A. W. Glisson, "Input impedance of aperture-coupled dielectric resonator antennas," IEEE Transactions on Antennas and Propagation, vol. 44, no. 5, pp. 600-607, 1996.

[10] Y. C. Chen and Y. W. Zeng, "Double-layered coplanar patch antenna on CaLa4Ti5O17 high-permittivity substrate with coplanar waveguide feed line," Microwave and Optical Technology Letters, vol. 51, no. 1, pp. 98-100, 2009.

[11] Y. C. Chen and J. M. Tsai, "Investigation on the use of highpermittivity substrate in stacked patch antenna fed by a coplanar waveguide," Microwave and Optical Technology Letters, vol. 51, no. 3, pp. 715-717, 2009.

[12] M. S. Al Salameh, Y. M. M. Antar, and G. Séguin, "Coplanarwaveguide-fed slot-coupled rectangular dielectric resonator antenna," IEEE Transactions on Antennas and Propagation, vol. 50, no. 10, pp. 1415-1419, 2002.

[13] K. W. Leung, K. M. Chow, and K. M. Luk, "Low-profile highpermittivity dielectric resonator antenna excited by a diskloaded coaxial aperture," IEEE Antennas and Wireless Propagation Letters, vol. 2, no. 1, pp. 212-214, 2003. 

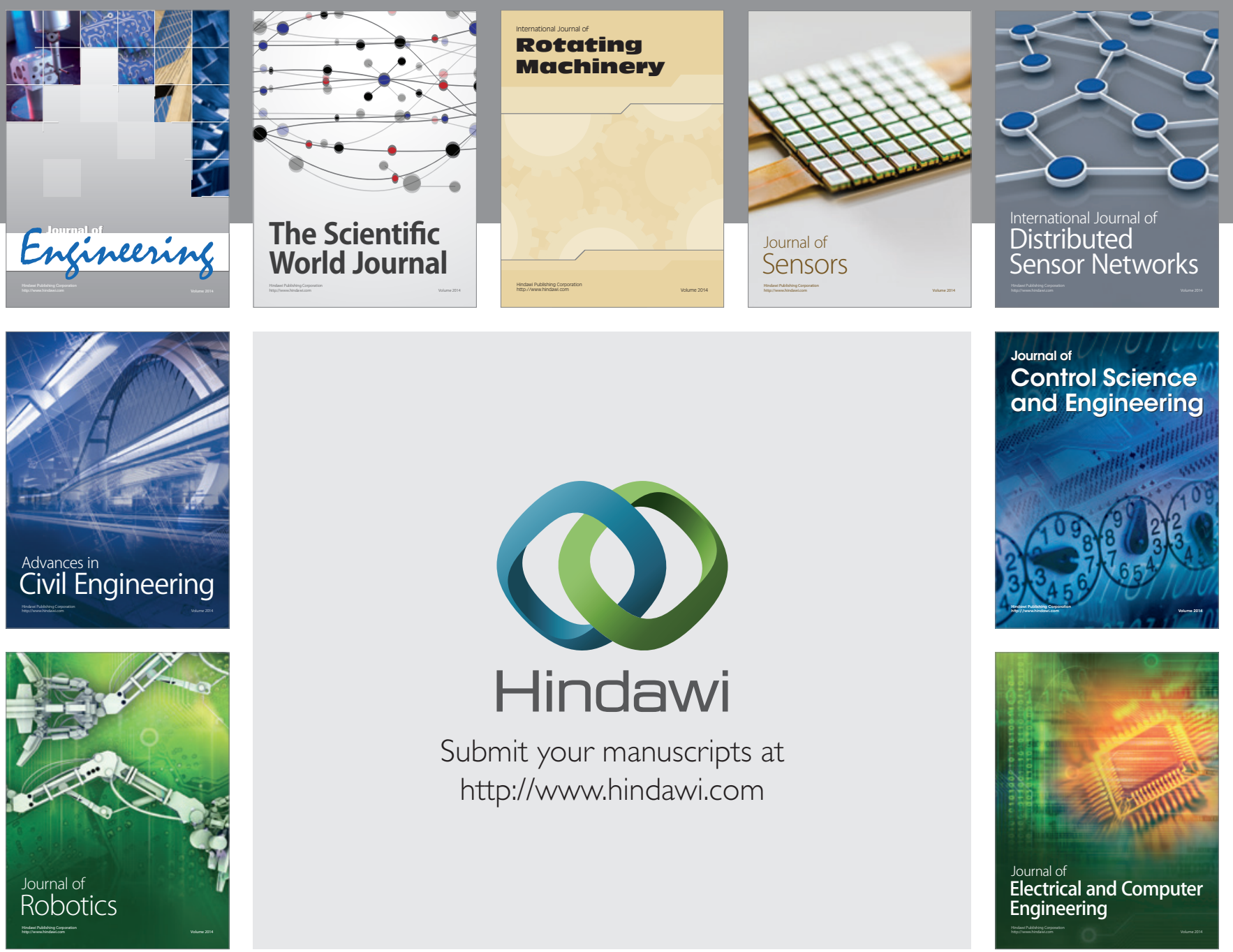

Submit your manuscripts at

http://www.hindawi.com
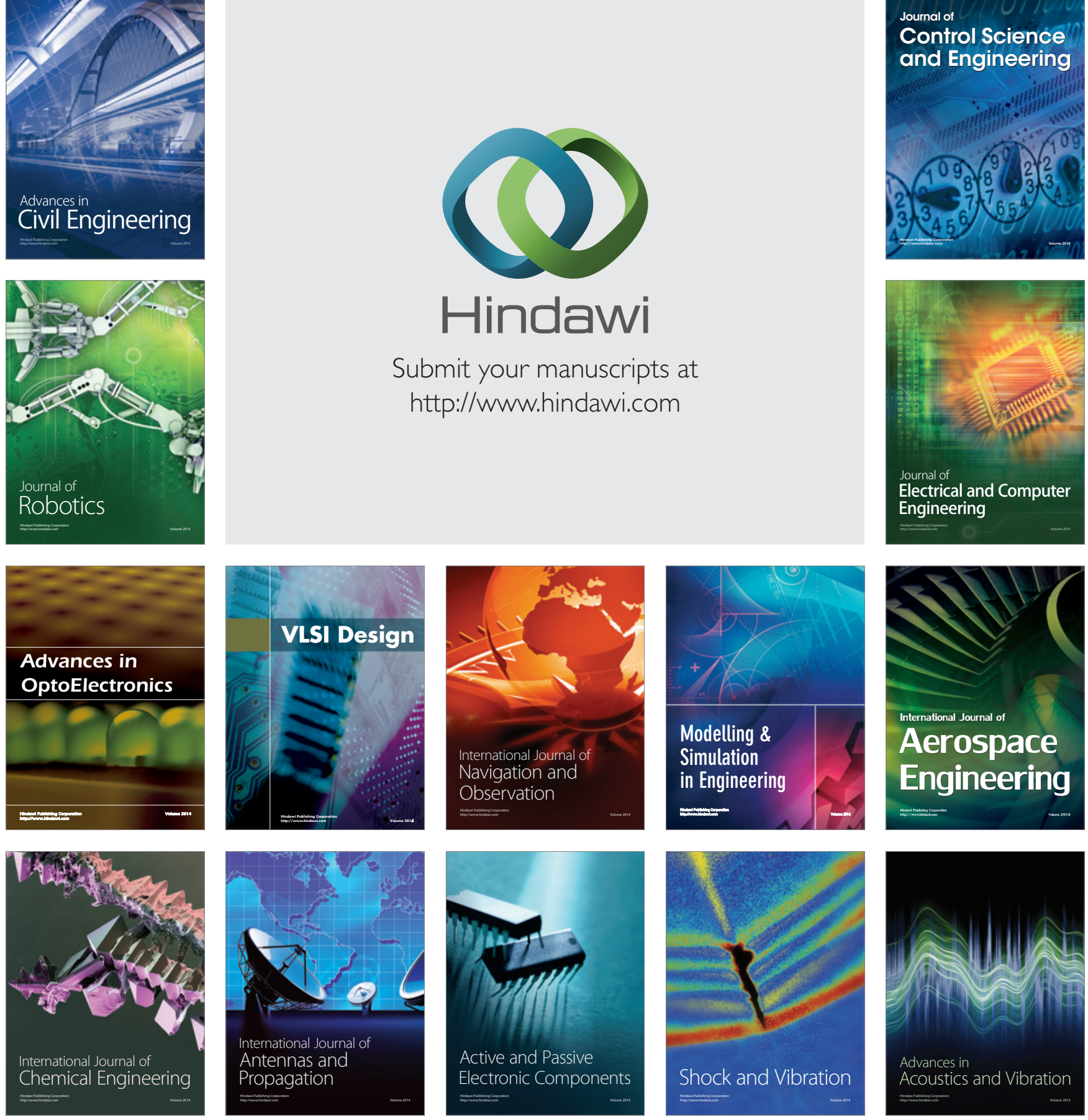